\title{
Synthesis
}

\section{Delivering 21st century Antarctic and Southern Ocean science}

\author{
M.C. KENNICUTT II, Y.D. KIM, M. ROGAN-FINNEMORE, S. ANANDAKRISHNAN, S.L. CHOWN, S. COLWELL, \\ D. COWAN, C. ESCUTIA, Y. FRENOT, J. HALL, D. LIGGETT, A.J. MCDONALD, U. NIXDORF, M.J. SIEGERT, \\ J. STOREY, A. WÄHLIN, A. WEATHERWAX, G.S. WILSON, T. WILSON, R. WOODING, S. ACKLEY, \\ N. BIEBOW, D. BLANKENSHIP, S. BO, J. BAESEMAN, C.A. CÁRDENAS, J. CASSANO, C. DANHONG, \\ J. DAÑOBEITIA, J. FRANCIS, J. GULDAHL, G. HASHIDA, L. JIMÉNEZ CORBALÁN, A. KLEPIKOV, J. LEE, \\ M. LEPPE, F. LIJUN, J. LÓPEZ-MARTINEZ, M. MEMOLLI, Y. MOTOYOSHI, R. MOUSALLE BUENO, \\ J. NEGRETE, M.A. OJEDA CÁRDENES, M. PROAÑO SILVA, S. RAMOS-GARCIA, H. SALA, H. SHIN, \\ X. SHIJIE, K. SHIRAISHI, T. STOCKINGS, S. TROTTER, D.G. VAUGHAN, J. VIERA DA UNHA DE MENEZES, \\ V. VLASICH, Q. WEIJIA, J.-G. WINTHER, H. MILLER, S. RINTOUL and H. YANG* \\ mckennicutt@gmail.com \\ *Author contact information and contribution are provided in Table S1 in the supplemental material found at \\ http://dx.doi.org/10.1017/S0954102016000481.
}

\begin{abstract}
The Antarctic Roadmap Challenges (ARC) project identified critical requirements to deliver high priority Antarctic research in the 21st century. The ARC project addressed the challenges of enabling technologies, facilitating access, providing logistics and infrastructure, and capitalizing on international co-operation. Technological requirements include: i) innovative automated in situ observing systems, sensors and interoperable platforms (including power demands), ii) realistic and holistic numerical models, iii) enhanced remote sensing and sensors, iv) expanded sample collection and retrieval technologies, and v) greater cyber-infrastructure to process 'big data' collection, transmission and analyses while promoting data accessibility. These technologies must be widely available, performance and reliability must be improved and technologies used elsewhere must be applied to the Antarctic. Considerable Antarctic research is field-based, making access to vital geographical targets essential. Future research will require continentand ocean-wide environmentally responsible access to coastal and interior Antarctica and the Southern Ocean. Year-round access is indispensable. The cost of future Antarctic science is great but there are opportunities for all to participate commensurate with national resources, expertise and interests. The scope of future Antarctic research will necessitate enhanced and inventive interdisciplinary and international collaborations. The full promise of Antarctic science will only be realized if nations act together.
\end{abstract}

Received 19 May 2016, accepted 19 August 2016, first published online 21 October 2016

Key words: access, future directions, infrastructure, logistics, technologies

\section{Introduction}

While the southern Polar Region of our planet is often perceived as being remote and distant from people's daily lives, events there are frequently reported in the media attracting wide public interest. As one of the largest remaining wildernesses on the planet, the region inspires a sense of awe and wonder. In contrast, the dramatic change being observed instills a foreboding of what the future holds as our planet rapidly warms. Knowledge to be gained in Antarctica and the Southern Ocean provides unique insights into some of society's most pressing concerns, including, but not limited to, climate change (global warming) and ocean acidification, sea level rise and threats to the planet's biodiversity (Chown et al. 2015, DeConto \& Pollard 2016). Building on nearly six decades of research since the International Geophysical Year 1957-1958 (IGY), the promise of future knowledge and insight to be gained by studying and understanding the Antarctic region has never been greater. Earth System science recognizes that the planet is a network of interconnected physical and living subsystems, and that perturbations in one region can reverberate throughout, having consequences for and invoking responses in, distal regions of the system. How these complex systems will respond in the future to 
human activities is incompletely understood at best and often unknown.

Over decades it has become increasingly apparent that the Antarctic is a critically important element of the planetary system (Barnes 2015, Summerhayes 2015). The Antarctic region not only responds to global change but in many instances is the epicentre and/or the origin of important processes that control or modulate global water, heat, energy and chemistry budgets. Antarctica and the Southern Ocean house one-of-a-kind sediment, rock, ice and fossil records of the Earth's history from 'deep time' to recent climate oscillations that provide a matchless window on the past and possible futures. The evolution and adaptation of Antarctic organisms, from the molecular to the population/ecosystem level, are unique on the planet and known to be influenced by climate change over millions of years (Chown et al. 2015). It is further known that a wide spectrum of stressors in the region are increasing in intensity and complexity (Kennicutt et al. 2014, 2015). The Earth System and how it has and will respond to anthropogenic stressors cannot be fully understood or predicted without operative understanding of Antarctica and the Southern Ocean, and their teleconnections to lower latitudes (Thompson et al. 2011). Understanding change in the Antarctic region, and why it is happening, is important to informing the global debate on the trajectory of Earth's environment and how decisions by humans will affect and alter future outcomes.

In recognition of the growing importance of Antarctic science and research in global debates, the international community came together in an unprecedented effort to define the highest priority scientific questions that can be uniquely addressed by studying the region (Kennicutt et al. 2014, 2015). The initial step was the Scientific Committee on Antarctic Research's (SCAR) Antarctic and Southern Ocean Science Horizon Scan (the Scan), which identified high priority scientific questions that researchers aspire to answer in the next 20 years and beyond (Kennicutt et al. 2014, 2015). The Scan was followed by the Council of Managers of National Antarctic Programs (COMNAP) Antarctic Roadmap Challenges (ARC) project designed to examine the steps necessary to enable the community to conduct research that will answer high priority scientific questions. Both of these exercises widely consulted the international Antarctic community to define a collective vision of one possible path to the future and what it will take to fully realize the promise of Antarctic research. The outcomes of ARC are reported here as a companion piece to the 'Antarctic Science Roadmap' (Kennicutt et al. 2015).

\section{The Antarctic and Southern Ocean Science Roadmap}

Collective international planning has a long history in Antarctic science, founded in the Antarctic Treaty of 1959 and four International Polar Years (IPYs). Dating to the 1800s, IPYs have been planned at 25-50 year intervals. International co-operation is a cornerstone of Antarctic science and reflects the spirit espoused by the Antarctic Treaty, which sets the geopolitical framework for consultative management of the region poleward of $60^{\circ} \mathrm{S}$. Over the years other conventions and agreements have established an international context for the conduct of science in and from Antarctica and the Southern Ocean.

The most recent IPY 2007-08 laid out a comprehensive portfolio of hundreds of programmes and projects that promoted international co-operation, data sharing and optimal use of science support activities (Krupnik et al. 2011, National Research Council 2012). However, Polar Years are infrequent. In order to provide a more regular opportunity for collective international planning a 'horizon scan' methodology was adopted, adapted, organized and managed by SCAR. A horizon scan has been described as ' $\ldots$ a priority-setting method that systematically searches for opportunities, which are then used to articulate a vision for future research directions'. The horizon scan methods of Sutherland et al. (2011, 2013) were customized to the requirements of Antarctic and Southern Ocean science, which is region-based and encompasses a wide range of scientific disciplines and research topics. The Scan was designed to be inclusive, democratic and transparent. The community was provided the opportunity to contribute scientific questions and to nominate experts to attend a retreat. At the retreat, invited experts prioritized the most pressing scientific questions and identified critical unknowns. A record of the Scan process and its outcomes are available in an archive (http://www. scar.org/horizonscanning).

The goal of the Scan was to systematically identify the most pressing, highest priority scientific questions that the global science community aspires to answer over the next two decades (Kennicutt et al. 2014, 2015). The primary output of the Scan was 80 high priority Antarctic scientific questions from nearly 1000 ideas generated by the community (Kennicutt et al. 2015). Once identified, scientific questions were organized into seven thematic clusters, each containing questions that were cross-cutting and interdisciplinary in scope: i) Antarctic atmosphere and global connections, ii) the Southern Ocean and sea ice in a warming world, iii) the ice sheet and sea level, iv) the dynamic earth beneath Antarctic ice, v) life on the precipice, vi) near-Earth space and beyond: eyes on the sky, and vii) human presence in Antarctica (Kennicutt et al. 2015).

\section{Delivering the science}

Defining the highest priority scientific questions was an important first step but the value of Antarctic research lies in answering the questions thereby producing new knowledge. The conduct of scientific research in the Antarctic region requires substantial and sustained investments by 
governments to meet the challenges of conducting research in a remote and extreme environment. Effectively navigating the 'Antarctic Science Roadmap' requires addressing a range of challenges. The ARC project answers the question: 'How will national Antarctic programmes meet the challenges of delivery of Antarctic science over the next 20 years?' As the entities that fund and support Antarctic science, national Antarctic programmes face many practical and technical issues. The ARC project translates high priority Antarctic research questions into actionable requirements for critical technologies, access, infrastructure and logistics.

Challenges to achieving the 'Antarctic Science Roadmap' are:

\section{Challenge 1: technology}

'Innovative experimental designs, new applications of existing technology, invention of next-generation technologies and development of novel air-, space- and animal-borne observing or logging technologies will be essential' (Kennicutt et al. 2015). Historically, science has been advanced by technological developments; notable is the emergence of aircraft and space-based technologies in the 20th century. New designs, instrumentation, sensor technologies (from micro- to macro-scale) and noncontaminating sample-retrieval technologies will continue to be required as scientists probe ever-more challenging locations to answer increasingly difficult questions. In many instances, technology makes science possible. Technological advances not only support ongoing science but may also limit what science can be performed and, in some cases, changes the scientific hypotheses that can be postulated (e.g. genomics has revolutionized ecology).

\section{Challenge 2: extraordinary logistics requirements (access)}

'Future research in Antarctica will require expanded, year-round access to the continent and the Southern Ocean' (Kennicutt et al. 2015). Antarctic logistics requirements are often complex and challenging. The geographical isolation, the extreme environmental conditions, the cost and the implementation of policy and reporting requirements make planning and logistics complicated and demanding on people, resources and time.

\section{Challenge 3: infrastructure}

'Antarctica and the Southern Ocean occupy a vast territory, much of which is inaccessible during winter. Even during summer the conditions prove challenging... infrastructure is essential to survival and is vital to the conduct of science. Two kinds of infrastructure can provide opportunities to advance scientific research in Antarctica: physical systems infrastructure, including transport, and cyber-infrastructure' (National Research
Council 2011a). The modern expansion of Antarctic infrastructure began during the IGY. Upgrades, refurbishments and the building of new stations and facilities have been implemented in the intervening years, especially during the IPYs. (For an inventory of current permanent scientific stations in Antarctica see https:// www.comnap.aq/Publications/Comnap\%20Publications/ comnap_map_edition5_a0_2009-07-24.pdf). Infrastructure implies a 'permanence' but there are also numerous temporary facilities, field camps, laboratories, air strips, fuel depots and traverse routes established for finite periods of time to support specific activities and/or science programmes. There remain vast regions of the Antarctic that are virtually unexplored, except by spaceborne sensors, where humans have never been. There are scientific questions that will require extensions into areas not now occupied or accessible. Environmental protection and conservation remains paramount and minimizing the 'human footprint' is a shared goal (Sánchez \& McIvor 2007, Sánchez \& Njaastad 2014).

\section{Challenge 4: international co-operation}

'Barriers to international collaboration need to be minimized ... mutually beneficial and efficient models for partnerships that share ideas, data, logistics and facilities need to be explored' (Kennicutt et al. 2015). The Scan outcomes highlighted the ever-increasing need for greater collaboration and partnerships between nations and scientific fields. International collaboration, interdisciplinary teams, partnerships between the private and public sectors, and close co-ordination between scientists and science support personnel remain fundamental requirements. Global Antarctic interests have grown beyond the original twelve Antarctic nations. As of 2016, 41 other countries have acceded to the Antarctic Treaty (http://www.ats.aq/index_e.htm). Scientific advice based on the knowledge generated by Antarctic research has been and will continue to be essential to informed decision- and policy-making, conservation and wise governance.

\section{Challenge 5: human resources}

'The polar science community should take advantage of the opportunity to develop innovative professional education efforts that build on the interdisciplinary and unique aspects of Antarctic research' (National Research Council 2011a). Concerns have been raised that insufficient numbers of scientists and engineers are being produced by educational systems to meet future demands (National Research Council 2007). Recently, several national Antarctic programmes noted that they are finding it increasingly difficult to recruit and retain people with the technical skills required for winter-over 
and field support positions. Establishing and sustaining stable funding to retain personnel and meet the needs of science and support is an emergent challenge. Public awareness, outreach and education are vital to sustaining the 'workforce pipeline'. In particular, there is growing global demand and competition for specialized skills in information, geospatial and communications technologies.

\section{Challenge 6: energy}

'Science operations in the Antarctic and Southern Ocean are energy-intensive ... new science technologies will require energy' (National Research Council 2011a). Today, most of the energy that powers Antarctic science and support is derived from fossil fuels. Vessels and aircraft are large users of fuel, and these demands will inevitably increase given calls for expanded and yearround access. Energy is required for materials and personnel transport, facilities operations, powering of instrumentation and observatories, and data collection, processing, storage and transmission. There are concerted efforts to improve energy efficiency, reduce demand and replace fuel with renewable wind and solar energy. New and/or improved battery technologies and more efficient use of energy in all aspects of Antarctic science are critical requirements for future Antarctic research.

\section{Challenge 7: long-term, sustainable funding}

'No one scientist, programme or even nation can reach these lofty aspirations alone, and success will be borne-out by the practical solutions delivered as we navigate our way together into an uncharted future' (Kennicutt et al. 2015). The cost of future Antarctic science and support activities will, in all likelihood, inexorably increase. Defining and exploring ways to enhance Antarctic science budgets to: i) support international collaborative projects, ii) long-term observations and observing networks, iii) ensure efficient utilization of limited resources and iv) encourage sharing and exchange of data, samples and information is critical. Sustained funding is essential to not only maintaining the current Antarctic community but critical to attracting and retaining the next generation of participants.

The ARC project addressed Challenges 1, 2, 3 and 4 enabling technologies, access, logistics and infrastructure, and international co-operation.

\section{Methodology}

The goal of ARC was to translate the high priority Antarctic and Southern Ocean scientific questions identified by the Scan into technological and operational requirements. The ARC project was designed to provide specificity to the high priority technological, access, logistic and infrastructure necessities that provide the greatest scientific return. Effort was made to achieve a consensus while prioritizing among the many possible options and needs. The objective of ARC was to communicate to, and raise awareness among, those who fund and deliver Antarctic science. Two open online surveys of the community were conducted. Survey 1 identified the highest priority technological needs ( $>400$ responses were received). Survey 2 asked the community to assess the feasibility and cost of the requirements identified in Survey 1 (> 250 responses were received).

Experts were then assembled at a workshop to consider a series of White Papers submitted by a range of Antarctic communities, ARC survey results and summaries from the Scan, as well as existing documents addressing future Antarctic science directions, technologies and logistics requirements. The 60 workshop participants included logisticians and operations experts, experienced Antarctic researchers, policy makers and national Antarctic programme personnel from 22 countries. The workshop was organized around the Scan science question clusters. Writing Groups were assigned co-Leads (one scientist/ researcher and one national Antarctic programme expert) and a scribe to record deliberations. Writing Groups were configured to maximize expertise, discipline, gender and geographical representation.

Each Writing Group was supplied with standardized forms containing a series of questions. By answering the questions, the Writing Groups methodically identified the highest priority technologies including: i) availability and the current status of development, ii) where geographically the technologies would be utilized, iii) the temporal scales and frequencies over which the technologies might be used and iv) how broadly applicable the technologies were for answering scientific questions. The Writing Groups also considered the requirements to deliver the science in terms of feasibility, cost and scientific benefits.

Writing Groups were asked to identify requirements that were particularly complex, required long-term investments to achieve and/or had associated costs that realistically could only be met (or be best accomplished) by international partnerships. Writing Groups were also asked to identify major trends (changes) in logistics, access and infrastructure requirements that will significantly impact long-term, strategic alignment of international capabilities, resources and capacity. In a concluding section, the Writing Groups were asked to summarize the most important 'take-home messages' for those that fund and support Antarctic research. Reports from each Writing Group were reviewed by external experts who had not been at the workshop and were subsequently revised to a final version. The final reports were analysed to discern high priority needs that support the broadest swath of the Antarctic community and have the greatest potential for optimal scientific return. 


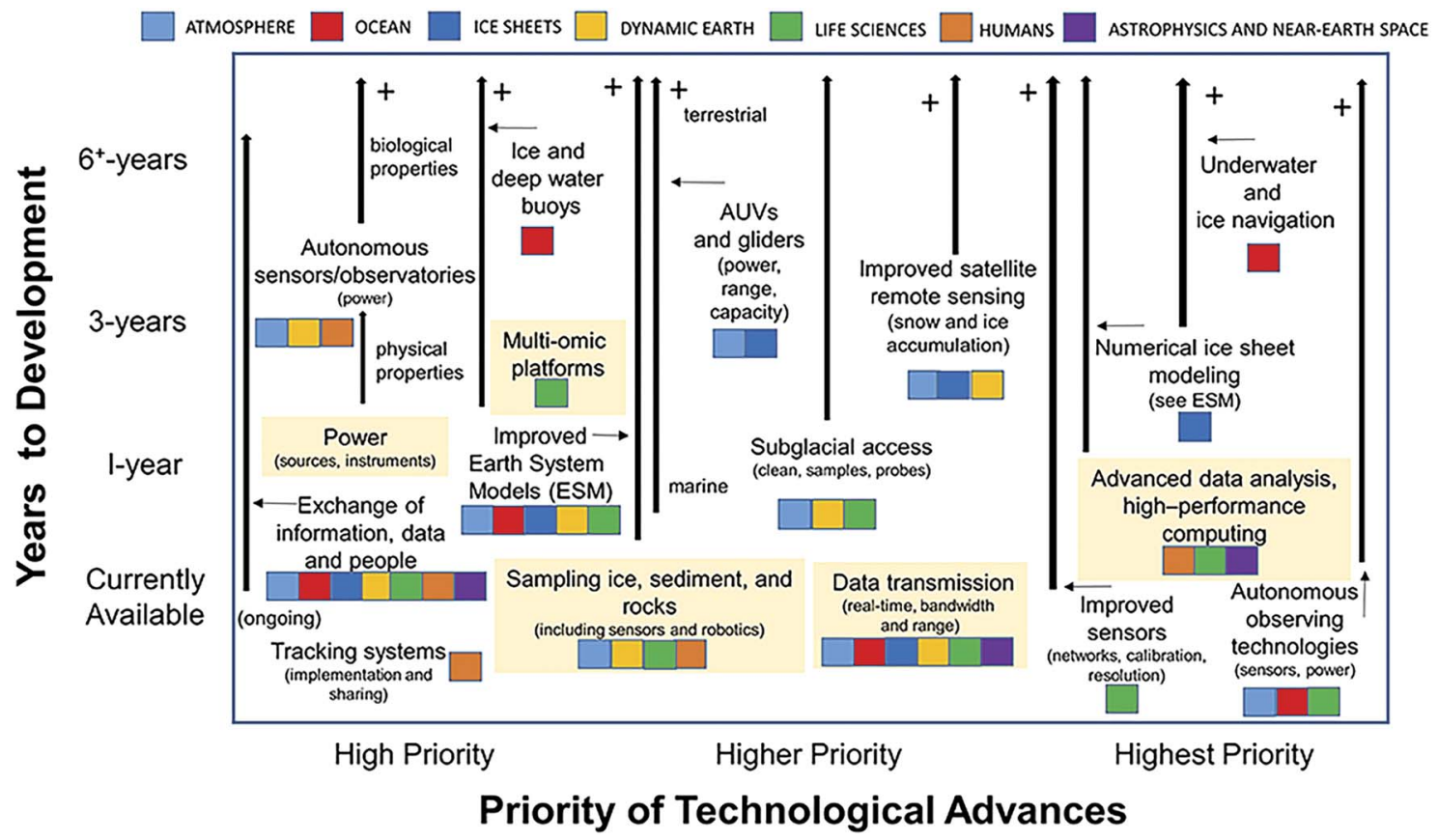

Fig. 1. Summary of online survey results prioritizing technological advances necessary to answer the highest priority Antarctic scientific questions. Technological advances are categorized on the X-axis from high to highest priority based on rankings by respondents. On the Y-axis, horizontal lines with arrows indicate the current status of the technology and, if under development, the estimated years to availability ( ' + ' at the upper end of the horizontal lines with arrows indicates that full development and availability is estimated to be in excess of six years from 2015). Coloured bar codes indicate which science clusters ranked the indicated technology as a priority need (see the colour key at the top of the figure). Note that coloured bar codes indicate highest priorities within scientific question clusters but the absence of a cluster does not indicate that the technology is not applicable, i.e. it did not rise to being highest priority for the cluster's specific scientific questions. Technologies highlighted by beige boxes include a wide range of associated or supporting technologies and therefore a time frame for development is not indicated as it is highly variable.

A record of ARC including: i) survey results, ii) workshop preparation materials and questionnaires, iii) White Papers, iv) final Writing Group reports and v) other supporting materials are archived at https://www. comnap.aq/Projects/SitePages/ARC.aspx, and the final Writing Group reports are provided in the supplemental material found at http://dx.doi.org/10.1017/S09541020 16000481 .

\section{Outcomes}

Technological requirements are first discussed on a 'scientific question cluster' basis followed by consideration of cross-cutting requirements (Fig. 1).

\section{Antarctic atmosphere and global connections}

The highest priority technological advances for Antarctic atmospheric sciences research are: i) expanded observing technologies capable of autonomous and/or sustained deployment (including adequate power supplies), ii) improved Earth System Models, iii) enhanced and expanded remote sensing capabilities, and iv) connectivity that allows for real-time data collection, transfer and analysis. Advances in Antarctic atmospheric sciences will be critically dependent on enhanced exchanges of people and information including better logistical co-ordination, technology transfer and dissemination, and open availability and co-ordination of data. Remote sensing is a particularly critical technology for answering high priority atmospheric science questions. The Antarctic community must therefore engage with national space and meteorological agencies to ensure their needs are represented in planning for future missions.

Continuous and robust sensors on automated weather systems (AWS) and unmanned aerial systems (UAS) are needed for 'smart' (unattended) deployment, and need to be complemented by new sensor technologies and new observational platforms (e.g. unmanned aerial vehicles (UAVs)). Improved and new battery technologies to meet the power requirements of autonomous systems are essential for long-term, sustained deployments and enhanced communications. Advances in power technologies will most probably occur in the private sector and the Antarctic community must be ready to rapidly adapt these technologies to applications in Antarctica.

Improvements in numerical models are needed to answer pressing atmospheric sciences questions, often 
requiring improved integration between observations and models. Advances in models are closely tied to the availability of cyber-infrastructure (e.g. high bandwidth), high-performance computing and open data. Critically, the range of components included in Earth System Models and their interconnections must be enhanced to provide more realistic forecasts. More advanced numerical models are needed to support 'system reanalysis' projects providing a resource for interdisciplinary science. Partnerships beyond the Antarctic community are essential to advance models including organizations such as the World Meteorological Organization's Experts on Polar and High Mountain Observations, Research and Services group, and national space and meteorological agencies that are addressing improvements in observations, Earth System Models and data availability. Enhanced linkages between atmospheric observations, modelling and operational forecasting is essential for improving regional and local weather forecasting, and enabling efficient planning of field operations. Improved co-ordination of operational meteorology activities among national programmes is especially needed to progress sea ice forecasting, for example.

\section{The Southern Ocean and sea ice in a warming world}

The highest priority technological requirements needed to advance Southern Ocean science are: i) underwater and under floating ice navigation and positioning, ii) automated underwater vehicles (AUVs), drones and gliders with greater range and capacity, iii) long-term ice and deep-water capable buoy networks including ice-tethered platforms/profilers, sea-ice buoys, drifters and moorings, iv) autonomous biological and physical sensors/observatories, and v) greater bandwidth and continuity of data communication from remote locations (e.g. underwater).

The trend in ocean sciences research, as in most fields, is greater automation of measurements. The performance of AUVs, gliders, drones, remotely operated vehicles and drifters continue to improve. Underwater and under-ice navigation and positioning must be more accurate for effective emplacement and tracking of observing platforms. Greater automation requires stable and longduration power supplies to expand temporal and spatial range. Smaller, more powerful batteries combined with miniaturized, energy efficient and less expensive sensors will be critical for long-range autonomous ocean (and atmosphere) sensing platforms. Prototype technologies exist but are not widely available.

Ocean moorings can be routinely deployed for about two years at present. In the future, deployments of five years or longer will be needed. This requires long lasting power supplies and stable, auto-calibrating sensors. Present drifter networks need to be adapted for use in under-ice, deep sea and shallow water environments. Icetethered platforms (including ice mass balance buoys) capable of longer duration emplacements are needed. Interoperable unmanned observatory hubs are needed that support a wide range of observations (weather stations, ice radar, ocean measurements cabled up from moorings, gliders, AUVs and buoy networks). These hubs must be capable of providing power, data collection and transmission of data from remote locations via satellite and/or air links. Cabled observatories are under development elsewhere in the world's oceans and application of these advances to studies in the Southern Ocean must be pursued (http://www.interactiveoceans. washington.edu/story/The_Cabled_Component_of_the_ NSF_Ocean_Observatories_Initiative).

Satellite-based sensors that provide long-term, yearround observations are critical for ocean research (http:// science.nasa.gov/earth-science/oceanography/). Ground truthing of data collected by satellite- and airborne sensors is a high priority and will require sustained, year-round access to the region. Presently, the only ways to obtain data from surface waters of Antarctica during winter are via satellites, airborne sensors and instrumented mammals. Automated collection of ground data during winter is important. Ethical, animal-based technologies need to be more widely available, less expensive, disposable and miniaturized.

Scientific questions relating to palaeoclimate and extreme events require the retrieval and study of deep sea, coastal and interior basin sediment records. Existing core drilling/recovery and sediment retrieval technologies are not readily available to Antarctic scientists due to the high cost of operation in the Antarctic region. Mobile, multi-purpose drilling rigs with advanced sampling, coring, sample retrieval and sensor array (down-borehole) technologies are needed.

Increased bandwidth and faster transfer of 'big datasets' from Antarctica are critical limitations for future Southern Ocean research. Data transmission through the ocean is a particular challenge. Presently, this is accomplished by cable, sonically (limited bandwidth) and/or by the release of data capsules to the surface. Enabling real-time or "nearreal-time' transfer of data via satellites and/or high altitude UAVs offer solutions.

\section{The ice sheet and sea level}

The highest priority technological advances that will be needed for accomplishing research to answer scientific questions related to ice sheets and sea level are: i) processdriven numerical ice sheet models, ii) subglacial (including sediment recovery) and englacial sampling and sensing methods, iii) combined, multiple geophysical measurement and sampling of ice including from UAS, iv) satellite sensors that can collect synoptic operational measurements of snow and ice accumulation, and v) improved AUVs, in-ice observatories and submersible sensors. 
Improved predictions of ice sheet change and response to forcings are essential (Church et al. 2013). The integration of models with a wide range of in-field observations will be critical to developing the next generation of ice sheet models capable of describing and predicting realistic ice flow. These improved models need to be an integral element of holistic Earth System Models. Model improvements are mostly hindered by a lack of observations of key processes. A better understanding of the influence of bed topography, ice fabric, basal heat flow, underlying sediments, temperature and other basic parameters is important for improving models. Comprehensive and more accurate ice sheet mass balance measurements are essential. Knowing the flow of ice in vertical profile in all places, from the interior to the grounding zone, is needed to adequately describe the factors that influence ice sheet dynamics. Ice sheet models have improved considerably but substantial advances are needed to better constrain predictions and to describe the 'real' flow of ice. The requisite observation requires englacial placement of sensors and observatories, analogous to AWSs, and may necessitate the use of disposable sensor arrays.

\section{The dynamic earth beneath Antarctic ice}

The technologies necessary to address high priority geosciences questions are: i) sensor arrays on the continent and in ice/subglacial boreholes, ii) improved capabilities for the collection of data and samples during field surveys (UAS, improved sampling technologies, and miniaturization and efficient power designs for sensors and robotics), and iii) drilling systems for the collection and complete recovery of samples of sediment and rock from beneath the ice, the land and the ocean. Many of these technologies exist/or are under development (National Research Council 2011b).

Key for the advancement of geosciences is wider availability of existing technologies that allow for regular/repeated collection of a wide range of samples and data at a wider range of sites. Transcontinental arrays of sensors are needed. Other technologies such as subglacial bedrock/sediment core recovery and remote sensing sensors need to be developed (Makinson et al. 2016). Geophysical data, sensors and samples will allow for a better understanding of the distribution and volumes of greenhouse gases stored in permafrost and clathrates. Samples of sediment and rock provide information about biota and ecosystem evolution over Earth's history.

Ensuring the standardization of sensor technology and the connectivity and interoperability of sensors is a high priority. Multi-sensor, multi-tasking observatories and platform networks that support integrated experiments across disciplinary boundaries will improve the efficiency of resource utilization. Sensor networks need to be capable of acquiring and transmitting high volumes of data and will require increased bandwidth.

Technology development is important for advancing subglacial research. Routine clean, rapid and reliable access through thick ice is required to repeatedly access the subglacial environment across the continent (Siegert et al. 2012). These methodologies must focus on minimizing environmental impact while maximizing scientific return without compromising the sites for future study. Portable drills, sampling devices and supporting laboratories are needed to establish a continent-wide network of subglacial observatories. Obtaining and returning uncontaminated samples (especially for biological samples) to the ice surface is essential.

\section{Life on the precipice}

The Antarctic life sciences cluster of questions spans marine to terrestrial (including subglacial) environments and requires studies of a range of organisms from viruses to marine mammals. High priority life sciences questions address a wide variety of themes in biology, ecology and conservation science. Life sciences priority technological requirements include: i) improved, robust, in situ, highresolution ecosystem monitoring sensor arrays (including the ability to automatically calibrate), ii) autonomous, multi-purpose, continuous and long-term in situ process monitoring systems and vehicles (including sample recovery and return capabilities), iii) high-performance computing capabilities for analysing 'big data', iv) high-volume automated multi-omic instrumentation (including automated in situ meta-genomic and integrated bioinformatics analyses), and v) high-volume bandwidth for data capture and analysis on- and off-site.

Addressing life sciences questions requires automated sampling devices and observatories equipped with improved and new sensors that can be deployed on platforms from ships to UAS to satellites. Oceanographic conditions must be measured during life sciences studies on spatial and temporal scales of relevance to biota and biotic processes (Gutt et al. 2015), requiring more demanding temporal and spatial sampling regimes than those utilized for the physical sciences. A key requirement will be to place observing and sensing platforms in scientifically interesting places at critical times. For example, rapid response teams might be assembled to respond to opportunistic seasonal events that are expected to have profound impacts on the trajectories of ecosystems; therefore, flexibility will be key.

Numerical modelling, bioinformatics, ecoinformatics and associated approaches will require increasing access to high-performance computing (Bersanelli et al. 2016). Accessibility of such computing, both in the Antarctic and at home institutions, is essential.

High speed communication via satellite, microwave and other technologies will be a significant requirement to 
deliver future life sciences research. Communications capabilities must reach to ships given their ongoing significance for deep sea work based on data collection by AUVs, UAS, buoy networks, drones and gliders. Antarctic researchers must stay abreast of technologies developed elsewhere in the world and be proactive in applying the latest and most sophisticated technologies to life sciences research.

The 'omic' approaches (e.g. genomic, transcriptomic, metabolomic) are critical for future Antarctic life sciences research (Berger et al. 2013). In situ omic platforms that allow real-time analysis and onward transmission of data (rather than samples) will need to be deployed across a range of geographical sites region-wide.

Life sciences research has a major role to play in Antarctic conservation efforts, particularly in the marine realm in support of the establishment of protected areas, setting of fishing quotas, ecosystem-based management schemes, and predicting the response of ecosystems to past and future resource extraction within the context of a changing and warming climate (Constable \& Doust 2009). Critical to life sciences research is improved ecosystems models linked to Earth System Models that connect environmental drivers to ecosystem structure and function and improving forecasts.

\section{Near-Earth space and beyond: eyes on the sky}

The highest priority technological challenges faced in using Antarctica as a platform to gaze into space are: i) high bandwidth networks on- and off-continent capable of continuous, real-time data transfers, i) energy efficient high-performance computing hardware and advanced data analysis techniques, iii) remote/robotic observatories, and iv) novel, transportable telescope designs (e.g. segmented mirrors, off-axis mirrors, lightweight (carbon fibre) mirrors and high-precision inertial pointing systems).

There are significant trade-offs between communications bandwidth and capability for on-site data processing. The former is dependent on the infrastructure provided by the national programmes, while the latter requires significant advances in energy efficient high-performance computing hardware and/or the availability of enhanced electrical power. Answers to the questions related to the Dark Universe and extra-terrestrial life will require the deployment of optical/infrared telescopes to the interior of Antarctica. Engineering risks for large telescopes will need to be addressed through a series of pathfinder experiments.

Science activities in the Antarctic also support the high latitude observations needed to understand fundamental aspects of coupling between the solar wind and Earth's atmosphere, ionosphere and magnetosphere. The vast geographical regions in both hemispheres provide access to a broad range of geophysical phenomena spanning magnetic and geographical latitudes from the sub-auroral zone to the polar caps at altitudes from the troposphere to near-Earth space. While the Northern Hemisphere is relatively well instrumented with regards to near-Earth space observations, the southern Polar Region is not, primarily because of the extreme Antarctic climate and the lack of manned facilities with infrastructure. The situation in the Southern Hemisphere is changing with the development of technologies that support autonomous measurement systems that can be deployed in remote locations and operate unattended for long periods of time in severe environments.

\section{Human presence in Antarctica}

Research addressing the human dimensions of the Antarctic encompasses a diverse set of questions that integrates the life sciences and a range of social sciences and humanities disciplines, including anthropology, economics, history, human geography, law, political sciences and social psychology. The integration of methods of inquiry from such a wide range of disciplines requires the availability of technologies including: i) advanced data analysis techniques (e.g. high-performance computing and greater bandwidth), ii) improved ecosystem models, iii) improved sampling and handling technologies, iv) better sensing and surveillance technologies (including autonomous tracking devices for vessels, landings, land vehicles and scientific expeditions), and v) 'smart' imaging and recording technologies.

High-performance computing for advanced modelling both in the life and social sciences is a key requirement. Better sensors and broader deployment, both in space and time, of sensors including robotic and automated sampling will be required to understand impacts. In marine environments, automated systems for understanding impacts will be essential, coupled with information on the scope and extent of resource extraction (Xu et al. 2014). Sensing, surveillance and tracking systems are needed to provide information on the movements of vehicles of all kinds and to understand visitor access to various sites. Coherent and systematic mapping of legacies (e.g. building remains and artefacts) in the Antarctic is essential. Open access to information about human activities in the Antarctic based on accepted codes of practice need to be more widely applied.

\section{Cross-cutting technologies}

There are technological requirements that are common across science themes and disciplines including: i) advanced observing systems, sensors and platforms (including airand satellite-borne sensors) that allow greater spatial and temporal coverage, ii) improved models, iii) enhanced sampling technologies, iv) 'big data' issues including collection, transmission, computational power for analyses 
and synthesis, and accessibility, and v) improved, more accurate coupled numerical models of all types (Fig. 1).

Observing systems and sensors include a wide range of technologies from those used within the solid Earth to those used sub- and within-ice to those used on satellites, balloons, aircraft and animals. The critical environmental properties and/or variables to be sensed are highly dependent on the scientific questions being asked and have been widely discussed by various communities (e.g. delineation of key variables; State of the Environment Committee 2011). Due to the broad demands, nextgeneration observatory platforms will need to be capable of supporting a diverse array of sensors that address multiple scientific objectives and allow for synoptic collection of data. Improved observing platforms and technologies must be capable of operating autonomously and sustainable for long-term (months to years) deployment continent- and ocean-wide at all times of the year. Multi-purpose systems and vehicles that are capable of continuous and long-term monitoring of in situ processes that can collect and return samples for ground truth are needed. Deployable automated sensor technologies will also need to collect data at finer temporal and spatial scales than currently available. Improved power supplies and usage are a central challenge that cross-cut a variety of technological priorities and it is probable that such advances will come from beyond the Antarctic community. Improved satellite remote sensing is also needed to provide synoptic region-wide observations. Almost all scientific disciplines and themes will greatly benefit from a broader range of sensing capabilities and in many instances the required spatial and temporal coverage can only be provided by space- and/or airborne instrumentation.

There has been, and will continue to be, a need for a wide variety of sample collections and measurements at diverse locations during all times of the year. Improvement and development of sample-retrieval technologies will be critical for future research. All types of samples are needed including ice, rock, sediment, water, air and biological specimens from bacteria to large animals to flora. There is a need for non-contaminating sampling technologies that recover pristine samples, eliminating artefacts due to sample collection, handling, storage and transport. In some instances, recovery and maintenance of samples at in situ conditions (e.g. temperature and pressure) may be desirable and/or required to ensure the integrity of sample properties. In other cases, on-site sample processing and analysis may be the only choice. Development of sample-retrieval technologies that can complement and be performed by observatory platforms will be needed. Because of the expense of sample collection, international repositories and archives need to be expanded to facilitate and maximize the use of samples, and to preserve samples either for analyses that are not yet feasible or for variables that may become of interest in the future.

Data accessibility and sharing is a universal need in international science. Many of the anticipated advances in technology will result in 'big data'. Access to greater computational power and speed will be critical for future Antarctic research. A continued emphasis on data sharing, distribution and standards is fundamental to modern Earth System science. Better and more integrated platforms for high-performance computing to handle the rapidly growing 'big data' requirements are needed and must be made more widely available. Such computing capabilities underpin modelling, experimental designs, automated data and image analysis, and bioinformatics. There are major challenges associated with producing and handling 'big data' and adequate bandwidth and transfer rates (including transfer under water) are among these. Technologies currently used in the private sector such as Google search and machine learning algorithms, GIS applications, targeted marketing and medical data utilization are adept at collecting and analysing 'big data' and these technologies need to be adapted for use in Antarctic science.

An integrated system science approach is crucial to improving modelling and forecasting capabilities across all disciplines and topics. Improved Earth System Models are needed for weather and climate modelling and data reanalyses, process-driven numerical modelling is essential for predicting the behaviour of all Antarctic physical systems (ice sheets, atmosphere, ocean and sea ice) and improved ecosystem models are needed to test hypotheses, design experiments and inform conservation management (e.g. Hay et al. 2015). Holistic, interconnected models of all system components will be essential. Modelling non-linear relationships and threshold responses remains a challenge to predictive capabilities. Historical records are essential for hindcasting and model testing.

\section{The status of technologies}

Once identified and prioritized, technologies were assessed as to whether they were available or under development (Fig. 1). If the latter, an assessment was made as to when they would be available: i) in the shortterm (1-3 years), ii) the medium-term (3-6 years), or iii) the long-term (6-9+ years) (Fig. 1). These analyses indicate where resources might best be invested for greatest scientific return and highlight opportunities for partnerships.

A number of technologies were determined to be currently available but only available to relatively few scientists. Other technologies are currently available but would be improved by refinement (i.e. data transmission in terms of bandwidth and real-time capabilities, data collection equipment and analysis techniques, and 
autonomous/robotic vehicles of various types). In other instances, technologies that do not exist are required, such as power systems to improve the range and duration of observatory deployments, advanced computing and novel sensors. Many technologies are under continual improvement and advances will incrementally occur over a number of years (e.g. accessing and sampling the subglacial environment). Integrated technologies and interoperable platforms that serve multiple purposes and support varied applications are essential in order to optimize investments. Improved numerical modelling was a high priority for all thematic groups. Numerical model sophistication, comprehensiveness and realism of forecasts is highly variable. Major hurdles facing modelling include: i) coupling models of various kinds and ii) availability and assimilation of data for testing. Advances in a number of technological areas will most probably come from outside of the Antarctic science community and the challenge is applying them to the southern Polar Regions (e.g. multi-omics platforms, computing capabilities and information technologies, and autonomous vehicles and robotics).

Several factors impact technology usage including availability, the need for improvements and the rapidity of application of technologies available elsewhere to Antarctic science. The pace of technological advancement is determined by the magnitude and rate of investment, and the ability and desire to co-ordinate and focus efforts and resources on high priority needs. Many high priority needs were similar across disciplines and scientific topics suggesting that concerted community-wide efforts will be most effective in achieving technological objectives (Fig. 1).

\section{Access, logistics and infrastructure}

Historically, field-based research has been a mainstay and necessity for the conduct of Antarctic research. Physical presence continues to be an essential expression of national geopolitical interests in the region and this is unlikely to change in the future. While automation and remote sensing are finding wide applications, in situ observations and sampling by scientists 'on the ground' will remain an indispensable feature of Antarctic research. As such, the emplacement and provisioning of scientist and support personnel in the region will continue to be a major financial cost and driver of priorities for national Antarctic programmes.

Geographical access, logistics and infrastructure requirements are intrinsically intertwined. The desire to access geographical locations is frequently balanced against the capabilities and cost to provide the logistics and infrastructure support necessary for the safe conduct of research. High priority scientific questions will require the support of research activities in locations that may not be best served by or be geographically close to existing permanent stations. Flexibility, versatility, adaptability and interoperability will be essential to efficiently meet the demands of future Antarctic research.

Geographical access has spatial and temporal components that can often be critical limiting factors in conducting research. To date, the preponderance of observations and measurements have been made during the summer due to the difficult operating environment during other times of the year. This status quo will evolve with greater automation and improvements in remote sensing capabilities; however, expanded year-round physical access will remain a major challenge. There is a particularly critical need for life sciences research to expand studies year-round. Plans are underway to expand deployment seasons, and teams have been successfully deployed beyond the traditional summer months. Answering many of the most pressing scientific questions will require continent- and ocean-wide access year-round. This has profound implications for decisions about future configurations and capabilities of logistical support and infrastructure.

Science conducted far from permanent stations will require greater automation of deployable observatories and platforms, the development of modular and relocatable laboratories/facilities, temporary stations and expeditionary-style field programmes. Portable devices to drill ice and rock, core sediments, collect samples and access sub-ice environments will be needed. In some instances, on-site laboratories will be required to preserve and/or analyse samples for ephemeral properties. Realtime production and analysis of data will allow for decision making and 'on the fly' designing of experiments. Temporary or permanent land stations and integrated traverse and aviation capabilities are needed for repeated access to the West Antarctic Ice Sheet (WAIS) and the interior of Antarctica to emplace and maintain observatories. Ice sheet and sea level observatories will need to be deployed at multiple, geographically disparate sites and established as long-term multi-year monitoring stations. Antarctic geosciences research will require continental-scale synoptic observations from sensor networks and integrated drilling/sampling and surveying campaigns to define patterns in crust and mantle structure, geothermal heat flux, isostatic adjustment and dynamic topography, and rates of geomorphological change. Temporary stations will be needed to deploy mobile, remote field parties and camps capable of supporting remotely operated sensors and rovers. The development of enhanced inland/plateau traverse capabilities is essential for astronomy and near-Earth space science.

Expanded ship-time will be needed to provide yearround access to the Southern Ocean, the sea-ice zone and coastal regions. Multidisciplinary cruises to collect synoptic measurements are essential. The availability 


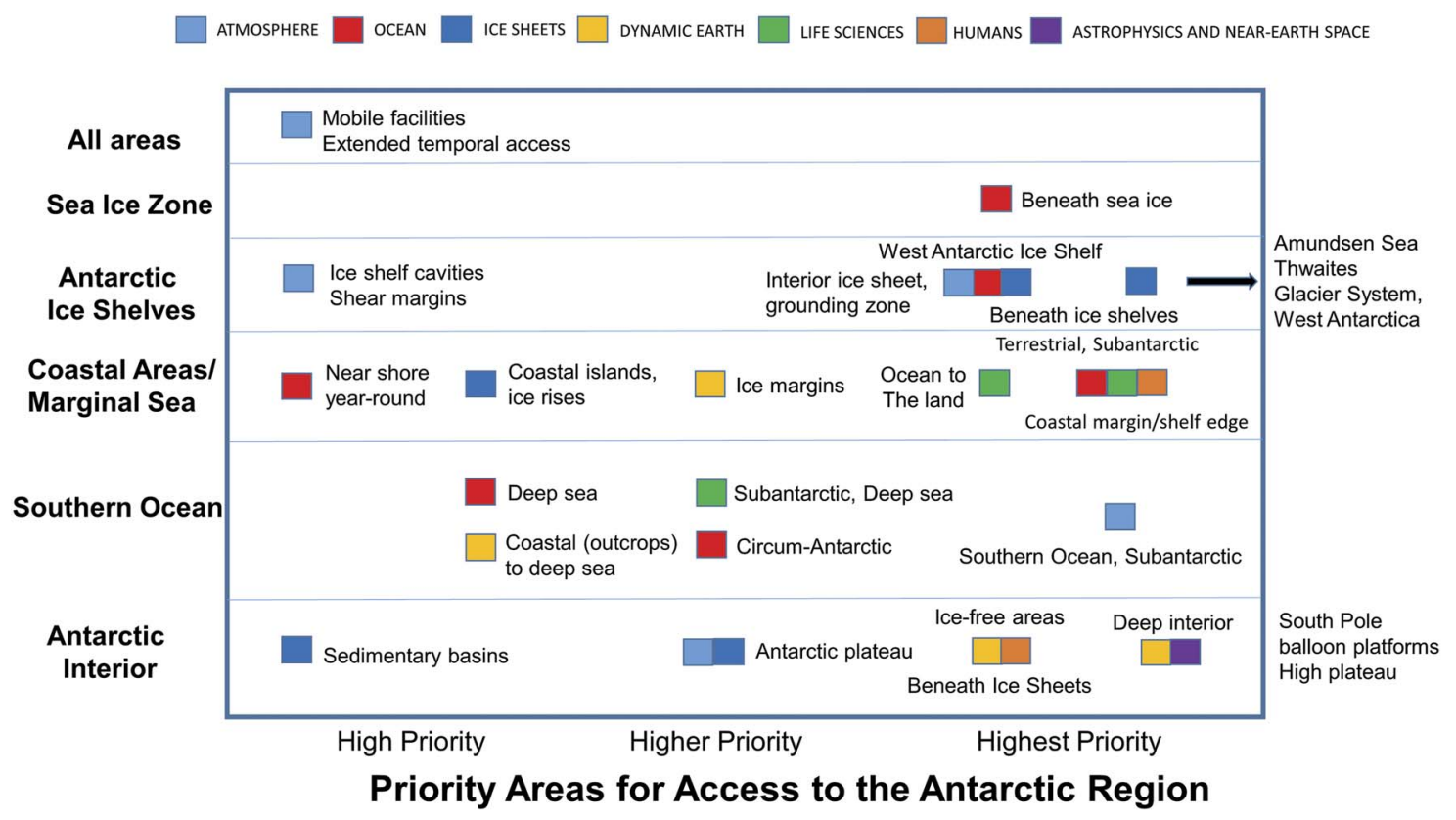

Fig. 2. Summary of survey results highlighting areas of the Antarctic region requiring greater access to answer the highest priority scientific questions. Colour coded bars indicate the Antarctic areas that need to be accessed to answer high priority scientific questions in specific areas of scientific interest (see colour code at the top of the figure). Note that the absence of a scientific cluster in the bar code does not indicate that these areas are not of interest, i.e. areas may be of interest but did not rise to the highest priority. An overarching conclusion is that year-round, and continent- and ocean-wide access will be essential for advancing Antarctic science in the future. Current areas of Antarctica experiencing accelerating environmental change are of high interest and areas of high scientific interest will evolve as scientific questions advance.

of ice-breakers is indispensable for high-resolution bathymetry mapping and deep sea drilling in ice-covered areas, to provide access to coastal research sites and for the provision of logistical support for interior stations and expeditionary field campaigns. There is a critical need for increased spatial and temporal access to the deep sea. Interoperable underwater docking ports are envisioned that will extend the range and utilization of AUVs, gliders and moorings. Docking stations must be capable of data collection and transmission, and the provision of power to sensors and observatories. These technologies are being developed and tested elsewhere in the world's oceans and adaptation to the Antarctic is essential (e.g. the Juan de Fuca Ridge).

Logistic hubs operated by multiple nations are needed to support air transport, ground traverses and fuel depots to incrementally expand geographical access and reach. These will allow research in the deep continental interior and remote coastal areas, in which sensor deployments, surveys, and drilling and sampling activities can take place. Logistics hubs must be scalable, and may be temporary, according to the science requirements. Such hubs will need to support a variety of transport modes including ski-equipped aircraft, helicopters, UAS and ground traverse capabilities. Consideration should be given to strategic placement of essential laboratory equipment around the continent and at sea, and the creation of shared analytical facilities possibly under international management.

\section{Geographical areas of high scientific interest}

Coastal areas (including beneath floating and grounded ice), the interior of Antarctica (including deep field camps) and the Southern Ocean are areas high current scientific interest for a wide variety of reasons (Fig. 2). One mechanism to improve efficiency would be the establishment of multinational 'super sites' for integrated studies.

Advances in atmospheric sciences research will require intensive spatial and temporal observations across the region including an expansion into areas of the Southern Ocean, the WAIS, difficult to access interior parts of East Antarctica and the sea-ice zone. Opportunistic access to all areas throughout the year should be capitalized on to make a wide range of atmospheric measurements. Data collected from the sea-ice zone is particularly important for understanding interactions between the cryosphere and atmosphere.

Areas of high interest for ocean research include the Ross Sea sector, coastal West Antarctica, Prydz Bay, Totten Glacier, the Amundsen Sea, the Weddell Sea sector and sub-Antarctic islands. Access needs stretch 
from the deep ocean, across the continental shelf, to nearshore environments (including ice shelf cavities). The highest priority access requirements for ocean research are: i) winter/year-round access to the continental margin/ shelf edge, including polynyas, ii) access beneath floating ice (sea ice and ice shelves), iii) circum-Antarctic coverage, iv) access to the deep sea, and v) year-round access to near-shore coastal areas. A challenge for ocean research is year-round access (in particular, winter access) requiring research-capable ice-breakers. Placement of semi-permanent ocean and sea-ice observatories is also a priority.

High priority regional and glaciological targets for ice sheet and sea level research are those which are particularly vulnerable to change. These regions are either currently contributing to sea level rise or are likely to do so in coming decades. Marine ice sheets (those parts of the ice that are grounded below sea level) and the associated grounding zones are regarded as most vulnerable to rapid and irreversible change. Current areas of high interest to sea level research are: i) the Amundsen Sea Embayment (Thwaites Glacier System) and other sectors in West Antarctica (e.g. Joughin et al. 2014), ii) marine margins to the interior of East and West Antarctica (including grounding zones, e.g. Totten Glacier in East Antarctica; Aitken et al. 2016), iii) the deep interior/Antarctic Plateau (where deep time records of past change in ice cores are held; e.g. Vance et al. 2016), iv) coastal islands and ice rises (that buttress grounded ice; e.g. Matsuoka et al. 2015), v) basins that influence the enhanced flow of ice and contain sedimentary records (e.g. Siegert et al. 2016), vi) ice shelf cavities and systems (that buttress grounded ice; e.g. Greenbaum et al. 2015), and vii) ice stream shear margins (Schroeder et al. 2016) that dictate the size and location of ice streams and where records of ice sheet change are likely to be recovered. Thwaites Glacier and its surrounding grounded ice and glaciers, ice shelves and the Amundsen Sea are currently undergoing rapid change and are high priorities for study. Marine ice sheets are linked to the interior reservoirs of the Antarctic ice sheet and understanding their contribution to sea level will require access to central Antarctica. The distribution of subglacial sedimentary basins and subglacial water influences the flow and stability of the ice sheet. Therefore, these basins and water accumulations are high priority targets for access. These basins may also contain unprecedented records of past climate changes that will improve our understanding of the response of the ice to climate forcings, the evolution and response of the interior of the continent during past warming periods and provide valuable retrospective testing of climate model reliability. Subglacial accumulations of water are expected to contain unique microbiological assemblages that have evolved under a range of extreme environmental conditions.
The stability and configuration of ice shelves that fringe marine ice sheets are important controls on the potential contribution of grounded ice to sea level change. Understanding ice shelves and the adjacent grounding lines requires access to a complex and dynamic region of sea ice and icebergs on the one hand and crevasses on the other. Access to this part of the system is critical and will require technological innovation and significant logistical effort. In a similar manner, lateral shear margins of glaciers (which separate rapidly from slow flowing ice) are poorly understood features of the ice sheet that need study. These areas are difficult to access because of crevasses but technologies similar to those proposed for grounding zones and ice shelves are applicable.

Access to the deep interior of the continent, especially in East Antarctica, is a high priority for studying supercontinent evolution. Access to West Antarctica is a priority for studying volcanism and its impact on the ice sheet. There is a critical need to visit interior sites to study rock exposures, deploy sensor networks, conduct airborne and other field surveys, and explore subglacial environments. Remote sensor networks need to be deployed, and sediment and bedrock beneath the ice sheet need to be sampled. Expanded airborne and geophysical surveys need to be conducted.

Access beneath the ice sheet continent-wide is a high priority to advance understanding of Antarctic glaciology and geology. Describing the subglacial geology of East Antarctica's interior is essential to understanding supercontinent evolution, and interior subglacial basins may contain unique climate records. Many of the largest accumulations of subglacial water are located in the continental interior (> 400 subglacial lakes have been identified to date). It is now known that these accumulations have unique and variable histories suggesting that microbiological life in the lakes may be highly variable in structure and function having responded to differing evolutionary and environmental forcings. Groundwater (i.e. water beneath the ice-bed interface) is a particularly understudied area of research (Christoffersen et al. 2014). Observatories need to be deployed in a wide range of subglacial environments to advance research objectives.

Access to coastal Antarctica, including the ice margins, is needed for collection of outcrop samples. The West Antarctic coast, particularly around the Amundsen Embayment and Marie Byrd Land, are mostly unknown. Access to the Southern Ocean from the coast to the deep sea is required to collect sediment and rock records of climate history, to study ice-ocean interactions, and to decipher the tectonic evolution of Antarctica/Gondwana. The Amundsen Sea Embayment, Wilkes Land, Ross Sea and Scotia Arc are key areas of study for the marine geology community. Networks and surveys over West Antarctica are needed to investigate 


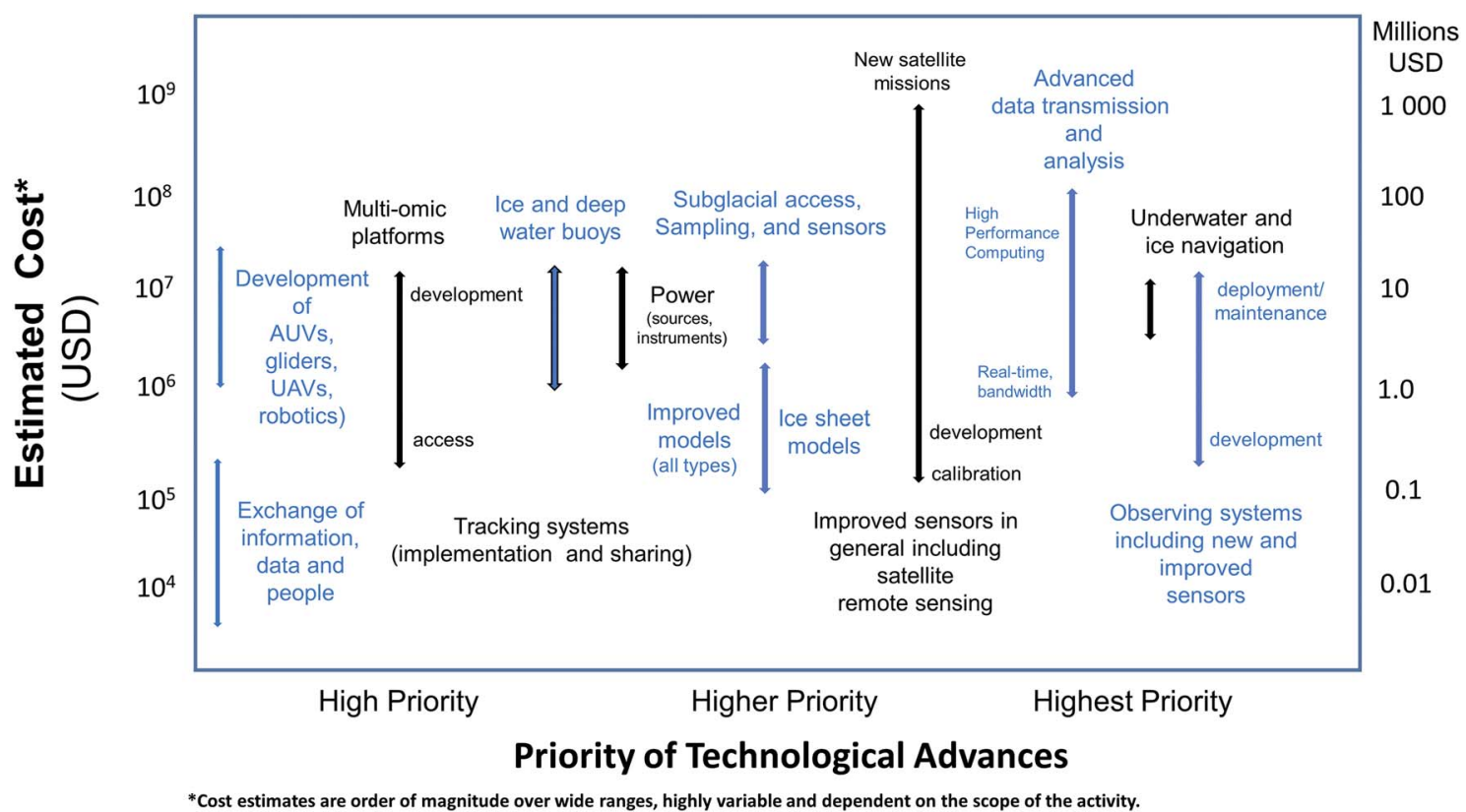

Fig. 3. Summary of survey results indicating qualitative estimates of the cost to develop and make available a range of high priority technologies judged to be essential to answering the highest priority Antarctic scientific questions. Horizontal bars with arrows indicate a range of possible costs which will be dependent on the scope and objectives of the development work undertaken. Costs will ultimately depend on finer delineation of the work involved by experts and these estimates are only provided as a general guide to the order of magnitude of the investment that may be involved. The survey results indicate a wide range of opportunities for investments in Antarctic science technologies commensurate with available resources and national interests.

the role of volcanism on evolving lithosphere, changing climate and ice sheet dynamics. Recent indication of the instability of the WAIS has major implications for possible future abrupt changes in global sea level. Continued participation in the International Ocean Discovery Program (IODP) will be important for Southern Ocean researchers' access to drilling technologies, down-borehole observations and retrieval of unique sedimentary samples.

Life sciences researchers will require access to all regions of the Antarctic continent, the Southern Ocean and sub-Antarctic islands. Current areas of high interest for life sciences researchers are coastal regions adjacent to terrestrial Antarctica, sub-Antarctic islands and the deep sea. Improved deep sea access is a high priority. Reliable access to terrestrial, freshwater and marine environments is a pressing need to increase understanding of the range and diversity of Antarctic biota.

Antarctica is a unique place for observations of the near-Earth space and beyond, and access requirements are related to: i) optimum placement of observatories, such as at South Pole Station, ii) locations to launch high altitude balloons, and iii) high plateau locations distant from disturbances. The ability to reach these remote areas (e.g. the high plateau), communications (e.g. wide bandwidth and continuous communication) and energy supplies for observatories to generate the tens of kilowatts of power needed for operation are high priority requirements.

Understanding anthropogenic change relative to other change requires access to high-impact (e.g. along the Antarctic Peninsula) and pristine sites to understand the ways in which changing patterns of activity in Antarctica are impacting the environment and how successful conservation efforts are in managing these impacts.

\section{The cost of Antarctic science}

There is a wide range in the human and financial resources that national Antarctic programmes invest in Antarctic science and support. While the overall expense of the requirements to realize the full potential of Antarctic science in the next two decades is great, there is a role for all interested parties to participate in ways that are commensurate with available resources, expertise and national interests (Fig. 3). Even the largest national Antarctic programmes will, by necessity, set priorities and concentrate on those advancements judged to support the widest scientific community while offering the greatest scientific return on investment. No one country or programme has the wherewithal to simultaneously pursue all aspects of the Antarctic Science Roadmap.

A wide range of opportunities are available with widely differing estimates of cost, depending on the scope of the 
activity undertaken (Fig. 3). At the lower end of the cost spectrum (tens of thousands to hundreds of thousands of US dollars) is data analysis and modelling. At the higher end of the cost spectrum (tens of millions to hundreds of millions of US dollars) is permanent infrastructure such as ships, stations and satellite missions. Partnerships, sharing of facilities and technologies, and co-ordination of efforts will be essential for maximizing return on investments. Development of high-cost technologies may require pooling of resources for greatest effect and partnerships may be most effective in establishing highdemand infrastructure and instrumentation in the region. There are a number of proven and successful models for countries to pool resources to accomplish shared objectives and interests (e.g. IODP, International Partnerships in Ice Core Sciences, Antarctic Geological Drilling, aircraft (e.g. Dronning Maud Land Air Network), and astronomy instrumentation and facilities).

Technological advances in many instances will be incremental, building on what others have accomplished, thus contributing to a larger effort may be most costeffective. An example is the development of sensors (here broadly defined) where advances could be accomplished by modest, targeted investments in specific technologies that once developed are then widely shared. Model development is often incremental and advances can be made by individual scientists contributing to a larger goal with co-ordination then being centrally important. These cost estimates suggest that there are abundant opportunities that are scalable to the resources available, allowing countries and scientists to participate individually or as members of international teams.

\section{International co-operation}

International collaborations, sharing of knowledge and data, co-ordination of logistics, advancement of enabling technologies, optimizing the utilization of infrastructure and partnerships are cost-efficient and indispensable if the full promise of Antarctic and Southern Ocean science is to be achieved. There is wide recognition that the breadth and depth of Antarctic research make many of the wished-for outcomes beyond the capabilities of individual researchers and projects, and often nations. The reality of finite and limited budgets and the necessity to bring talent and expertise to bear, regardless of location, are important reasons for working together for mutual benefit and greatest effect.

There is much value to be gained through co-ordination and collaboration between disciplines. Infrastructure and logistics designed for one objective (e.g. sub-sea ice marine water surveys) must be adapted and broadened to accomplish other objectives (e.g. biological surveys). Co-ordination with national space and meteorological agencies and the remote sensing community is vital for improving and creating new satellite sensors, applications and observations, and increasing spatial and temporal coverage. Co-operation among national providers is key to accomplish 'big science' and for expanding access to remote regions year-round. Improved co-ordination of Antarctic science interest with non-polar commercial and governmental organizations will be critical to developing and applying new technologies. Enhanced collaborations will encourage data sharing and wider access to stations, logistics and operational activities.

It will be important to engage skills, capabilities and capacities across national programmes, particularly in regard to fast-developing and technology-intensive research, through researcher exchange programmes and capacity building. 'Super sites' of high scientific interest are recommended as locations where the community comes together to establish transdisciplinary projects and programmes. These sites would create synergy and be cost-effective by measuring and observing a wide range of variables within synoptic and holistic study designs. Related to this is the creation of logistics hubs and interoperable nodes that could support a range of sensors and provide the necessary cyber-infrastructure for communications and data collection and transmission. In some instances, international management may be the best choice.

In this context, international organizations, such as SCAR promoting and co-ordinating scientific research, COMNAP co-ordinating operations and the Antarctic Treaty's Committee on Environmental Protection leading environmental protection, conservation and data exchange efforts, will play important roles.

An important emerging trend over the last two decades is regional alliances of national Antarctic programmes (e.g. Red de Administradores de Programas Antárticos Latino Americanos the network of managers of the LatinAmerican Antarctic programmes and the Asian Forum for Polar Science). These alliances promote regionalbased partnerships that share values and cultures, and often allow scientists to communicate in their native language.

\section{Conclusions}

At the dawn of the 21st century, Antarctic and Southern Ocean science has never been more important and relevant to pressing global debates about the future of Earth. Therefore, it is important to consider how to maximize Antarctic research returns and knowledge production. This will require prioritization, collaboration and sharing of results and resources. Critical understanding of the Earth System can only be, or is best, advanced by more integrated and holistic studies of the Antarctic region and its role in planetary processes. The window on the past preserved in Antarctic ice, sediment and rock records, and observations 
of ongoing changes will permit more constrained, accurate and realistic forecasts of future planetary trajectories. Important issues that are poised for major advances in understanding include: i) couplings between atmospheric, oceanic and land processes, ii) ice sheet flow behaviour and dynamics, iii) the forces that modulate planetary ice, water, heat and chemical budgets, iv) the controls on sea level, v) lithosphere and planetary evolution, vi) the interplay of evolution, physical forcings, and adaptation and functioning, biochemistry and structure of living organisms and ecosystems, vii) the drivers of biodiversity, viii) the impact and origins of anthropogenic perturbations, and ix) cosmology.

As has been true in the past, it can be expected that technological advances will profoundly affect the nature, conduct and scope of future Antarctic science, and the pace of technological change has never been greater. In all likelihood the research conducted in the Antarctic in 20 years will be considerably different than it was in the 20th century. The challenge is to apply the coming advances in instrumentation and sensors, automation, remote sensing and information technologies, and the emerging trends in 'big data' collection, analysis and transmission to Antarctic science. A recurring and underpinning guiding principle is to achieve the wishedfor outcomes within a framework of environmental stewardship. Future decisions must carefully consider the probable impact of planned actions on the environment and how these impacts can be minimized through efficiencies, innovative approaches and prevention. The preservation and conservation of societal, aesthetic and scientific values in the region will be best served by a goal of 'doing no harm'. The question is, will the Antarctic community be prepared and visionary in keeping pace with this unprecedented transformation?

To accomplish the ambitious "Antarctic Science Roadmap', the collection of a wide and diverse set of observations, samples and data from environments that span the southern Polar Region will be required. High priority Antarctic science questions will be best answered by programmes and projects that are interdisciplinary in scope, international in participation, and continent- and ocean-wide in reach. The mix of future Antarctic science projects and programmes will need to include focused projects that address important unknowns with targeted process studies and censuses in a wide variety of virtually unstudied environments. New ways must be developed to observe and quantify a wide range of physical and living system attributes on finer spatial and temporal scales in 4-dimensions and at high frequencies. Increasingly these observations and sensors will need to be automated and deployed for long durations enabling year-round data collections. Once observations, samples and data are collected, a wide range of cyber-infrastructure, information and geospatial analysis technologies will be needed to retrieve, process, synthesize, preserve and transmit data (e.g. from remote locations on the continent, in situ instruments, remote sensors and observatories, and on ships). Energy delivery technologies will be needed to extend capabilities to allow year-round and multi-year deployments of automated sensors and integrated observing platforms. The challenges facing the handling of the 'big data' that will be generated are many including adequate cyber-infrastructure and high-performance computing analysis, synthesis and the assimilation of observations and data into models.

The promise of future knowledge and insights to be gained by research in and from the Antarctic, and how it both reflects and affects global changes, will only be realized if the challenges of improvements in and development of new technologies, facilitation of access across the region year-round, and provision of the requisite logistical support and infrastructure can be addressed. The expansive, community vision of the future expressed in the Antarctic and Southern Ocean Horizon Scan and the ARC project can only be realized if the growing global family of Antarctic nations acts together.

\section{Acknowledgements}

The authors recognize the financial support that made the Scan and ARC possible. The Council of Managers of National Antarctic Programs (COMNAP), the Tinker Foundation and the Scientific Committee on Antarctic Research (SCAR) provided the majority of the funding for this project including the costs of travel and participation of invited, non-COMNAP workshop attendees. In-kind support was provided by many COMNAP-Member national Antarctic programmes including Dirección Nacional del Antártico (DNA, Argentina), Australian Antarctic Division (AAD, Australia), Programa Antártico Brasileiro (PROANTAR, Brazil), Instituto Antártico Chileno (INACH, Chile), Polar Research Institute of China (PRIC, China), Instituto Antártico Ecuatoriano (INAE, Ecuador), Institut Polaire Français Paul Emile Victor (IPEV, France), Alfred Wegener Institute (AWI, Germany), National Institute of Polar Research (NIPR, Japan), Korea Polar Research Institute (KOPRI, Republic of Korea), Antarctica New Zealand (New Zealand), Arctic and Antarctic Research Institute (AARI, Russia), Spanish Polar Committee (CPE, Spain), British Antarctic Survey (BAS, UK), and the US National Science Foundation (NSF, USA). The support of the COMNAP Secretariat, the SCAR Secretariat, and the staff at the Norwegian Polar Institute who hosted the workshop is gratefully recognized. The authors thank seventeen reviewers for their constructive comments that improved the Writing Group reports. Finally, thank you to those who provided topical White Papers for consideration. The authors also thank two anonymous reviewers. 


\section{Supplemental material}

Author contact information and contribution, and the final Writing Group reports will be found at http://dx.doi. org/10.1017/S0954102016000481.

\section{References}

Aitken, A.R.A., Roberts, J.L., van Ommen, T.D., Young, D.A., Golledge, N.R., Greenbaum, J.S., Blankenship, D.D. \& Siegert, M.J. 2016. Repeated large-scale retreat and advance of Totten Glacier indicated by inland bed erosion. Nature, 533, 385-389.

Barnes, D.K.A. 2015. Antarctic sea ice losses drive gains in benthic carbon drawdown. Current Biology, 25, R789-R790.

Berger, B., Peng, J. \& Singh, M. 2013. Computational solutions for omics data. Nature Reviews Genetics, 14, 333-346.

Bersanelli, M., Mosca, E., Remondini, D., Giampieri, E., Sala, C., Catsellani, G. \& Milanesi, L. 2016. Methods for the integration of multi-omics data: mathematical aspects. BMC Bioinformatics, 17, 10.1186/s12859-015-0857-9.

Church, J.A., Clark, P.U., Cazenave, A., Gregory, J.M., Jevrejeva, S., Levermann, A., Merrifield, M.A., Milne, G.A., Nerem, R.S., Nunn, P.D., PAyne, A.J., Pfeffer, W.T., Stammer, D. \& Unnikrishnan, A.S. 2013. Sea level change. In Stocker, T.F., Qin, D., Plattner, G.-K., Tignor, M., Allen, S.K., Boschung, J., Nauels, A., XIA, Y., Bex, V. \& Midgley, P.M., eds. Climate change 2013: the physical science basis. Contribution of Working Group I to the Fifth Assessment Report of the Intergovernmental Panel on Climate Change. Cambridge: Cambridge University Press, 1137-1216.

Chown, S.L., Clarke, A., Fraser, C.I., Cary, S.C., Moon, K.L. \& McGeOCH, M.A. 2015. The changing form of Antarctic biodiversity. Nature, 522, 427-434.

Christoffersen, P., Bougamont, M., Carter, S.P., Fricker, H.A. \& TulaCZYK, S. 2014. Significant groundwater contribution to Antarctic ice streams hydrologic budget. Geophysical Research Letters, 41, 2003-2010.

Constable, A.J. \& Doust, S. 2009. Southern Ocean Sentinel - an international program to assess climate change impacts on marine ecosystems: report of an international Workshop, Hobart, April 2009 ACE CRC, Commonwealth of Australia, and WWF-Australia. http:// awsassets.wwf.org.au/downloads/mo005_southern_ocean_sentinel_ lapr09.pdf. Accessed 31 May 2016.

DeConto, R.M. \& Pollard, D. 2016. Contribution of Antarctica to past and future sea-level rise. Nature, 531, 591-597.

Greenbaum, J.S., Blankenship, D.D., Young, D.A., Richter, T.G., Roberts, J.L., Aitken, A.R.A., Legresy, B., Schroeder, D.M., Warner, R.C., van OMmen, T.D. \& Siegert, M.J. 2015. Ocean access to a cavity beneath Totten Glacier in East Antarctica. Nature Geoscience, 8, 294-298.

Gutt, J., Bertler, N., Bracegirdle, T., Buschmann, A., Comiso, J., Hosie, G., Isla, E., Schloss, I.R., Smith, C.R., Tournadre, J. \& XAvier, J.C. 2015. The Southern Ocean ecosystem under multiple climate stresses - an integrated circumpolar assessment. Global Change Biology, 21, 1434-1453.

Hay, C.C., Morrow, E., Kopp, R.E. \& Mitrovica, J.X. 2015. Probabilistic reanalysis of twentieth-century sea-level rise. Nature, 517, 481-484.

Joughin, I., Smith, B.E. \& Medley, B. 2014. Marine ice sheet collapse potentially under way for the Thwaites Glacier basin, West Antarctica. Science, 344, 735-738.

Kennicutt, M.C., Chown, S.L., Cassano, J.J., Liggett, D., Massom, R., Peck, L.S., Rintoul, S.R., Storey, J.W.V., Vaughan, D.G., Wilson, T.J. \& Sutherland, W.J. 2014. Polar research: six priorities for Antarctic science. Nature, 512, 23-25.
Kennicutt, M.C., Chown, S.L. Cassano, J.J. \& 72 others. 2015. A roadmap for Antarctic and Southern Ocean science for the next two decades and beyond. Antarctic Science, 27, 3-18.

Krupnik, I., Allison, I., Bell, R., Cutler, P., Hik, D., López-Martínez, J., Rachold, V., Sarukhanian, E. \& Summerhayes, C. eds. 2011. Understanding Earth's polar challenges: International Polar Year 2007-2008. Edmonton, AB: CCI Press, Canadian Circumpolar Institute, 719 pp.

Makinson, K., Pearce, D., Hodgson, D.A., Bentley, M.J., Smith, A.M., Tranter, M., Rose, M., Ross, N., Mowlem, M., Parnell, J. \& SIEGERT, M.J. 2016. Clean subglacial access: prospects for future deep hot-water drilling. Philosophical Transactions of the Royal Society, A374, 10.1098/rsta.2014.0304.

Matsuoka, K., Hindmarsh, R.C.A., Мoholdt, G., Bentley, M.J., Pritchard, H.D., Brown, J., Conway, H., Drews, R., Durand, G., Goldberg, D., Hattermann, T., Kingslake, J., Lenaerts, J.T.M., Martin, C., Mulvaney, R., Nicholls, K.W., Pattyn, F., Ross, N., Scambos, T. \& Whitehouse, P.L. 2015. Antarctic ice rises and rumples: their properties and significance for ice-sheet dynamics and evolution. Earth-Science Reviews, 150, 724-945.

National Research Council. 2007. Rising above the gathering storm: energizing and employing America for a brighter economic future. Washington, DC: National Academies Press, 592 pp.

National Research Council. 2011a. Future science opportunities in Antarctica and the Southern Ocean. Washington, DC: National Academies Press, 230 pp.

National Research Council. 2011b. Scientific ocean drilling: accomplishments and challenges. Washington, DC: National Academies Press, 158 pp.

National Research Council. 2012. Legacies and lessons of the International Polar Year 2007-2008. Washington, DC: National Academies Press, 137 pp.

SÁnchez, R.A. \& McIvor, E. 2007. The Antarctic Committee for Environmental Protection: past, present, and future. Polar Record, $\mathbf{4 3}$, 239-246.

SÁnchez, R.A., NJAAstad, B. 2014. Future challenges in environmental management of National Antarctic Programs. In Tin, T., Liggett, D., MaHer, P.T. \& LAMERs, M., eds. Antarctic futures: human engagement with the Antarctic environment. Dordrecht: Springer, 287-306.

Schroeder, D.M., Grima, C. \& BlanKenship, D.D. 2016. Evidence for variable grounding-zone and shear-margin basal conditions across Thwaites Glacier, West Antarctica. Geophysics, 81, 10.1190/geo20150122.1.

Siegert, M.J., Ross, N., Li, J., Schroeder, D., Rippin, D., Ashmore, D., Bingham, R. \& Gogineni, P. 2016. Controls on the onset and flow of Institute Ice Stream, West Antarctica. Annals of Glaciology, 10.1017/ aog.2016.17.

Siegert, M.J., Clarke, R.J., Mowlem, M., Ross, N., Hill, C.S., Tait, A., Hodgson, D., Parnell, J., Tranter, M., Pearce, D., Bentley, M.J., Cockell, C., Tsaloglou, M.-N., Smith, A., Woodward, J., Brito, M.P. \& Waugh, E. 2012. Clean access, measurement, and sampling of Ellsworth Subglacial Lake: a method for exploring deep Antarctic subglacial lake environments. Reviews of Geophysics, 50, 10.1029/2011RG000361.

State of the Environment Committee. 2011. Australia state of the environment 2011. Chapter 7 Antarctic Environment. Independent report to the Australian Government Minister for Sustainability, Environment, Water, Population and Communities. Canberra: DSEWPaC, 2011. http://www.environment.gov.au/science/soe/2011report/7-antarctic/contents. Accessed 31 May 2016.

Summerhayes, C.P. 2015. Earth's climate evolution. Oxford: WileyBlackwell, 416 pp.

Sutherland, W.J., Fleishman, E., Mascia, M.B., Pretty, J. \& RudD, M.A. 2011. Methods for collaboratively identifying research priorities and emerging issues in science and policy. Methods in Ecology and Evolution, 2, 238-247. 
Sutherland, W.J., Freckleton, R.P., Godfray, H.C.J., Beissinger, S.R., Benton, T., Cameron, D.D., Carmel, Y., Coomes, D.A., Coulson, T., Emmerson, M.C., HaILS, R.S., Hays, G.C., Hodgson, D.J., Hutchings, M.J., Johnson, D., Jones, J.P.G., Keeling, M.J., KokKo, H., Kunin, W.E., Lambin, X., Lewis, O.T., Malhi, Y., Mieszkowska, N., MilnerGulland, E.J., Norris, K., Phillimore, A.B., Purves, D.W., Reid, J.M., Reuman, D.C., Thompson, K., Travis, J.M.J., Turnbull, L.A., Wardle, D.A. \& Wiegand, T. 2013. Identification of 100 fundamental ecological questions. Journal of Ecology, 101, 58-67. Thompson, D.W.J., Solomon, S., Kushner, P.J., England, M.H., Grise, K.M. \& Karoly, D.J. 2011. Signatures of the Antarctic ozone hole in Southern Hemisphere surface climate change. Nature Geosciences, 4, 741-749.
Vance, T.R., Roberts, J.L., Moy, A.D., Curran, M., Tozer, C.R., Gallant, A.J.E., Abram, N.J., van Ommen, T.D., Young, D.A., Grima, C., Blankenship, D.D. \& Siegert, M.J. 2016. Optimal site selection for a high-resolution ice core record in East Antarctica. Climate of the Past, 12, 595-610.

Xu, G., Shen, W. \& WAnG, X. 2014. Applications of wireless sensor networks in marine environment monitoring: a survey. Sensors, 14, $16932-16954$. 